\title{
Diagnóstico da produção de morango em Santa Catarina em 20151
}

\author{
Anyela Mayerly Rojas-Molina², Cristina Pandolfo ${ }^{3}$, Wilian da Silva Ricce ${ }^{3}$ e Aparecido Lima da Silva ${ }^{4}$
}

Resumo - O presente trabalho teve por objetivo identificar e quantificar a área cultivada, número de famílias envolvidas na produção e a quantidade produzida de morangos no ano de 2015 no estado de Santa Catarina. O trabalho incluiu o levantamento de informação e coleta de dados a campo, através da aplicação de questionários os quais foram respondidos por extensionistas da Epagri. As seis Mesorregiões do IBGE apresentaram produção comercial e para autoconsumo. No total, 725 famílias estiveram envolvidas com a produção comercial de morango. Aproximadamente $9918 \mathrm{t}$ de morango foram produzidas em 225,3ha. A cultura apresenta grande potencialidade quanto aos altos rendimentos encontrados em decorrência das respostas obtidas no questionário, sendo a média estimada de 35,6 a 38,6t ha-1 (IC=95\%). Os resultados obtidos em 2015 foram contrastados com dados da safra de 2016-2017 em algumas regiões do Estado, as quais mostram diminuição na área de cultivo do morangueiro, mas aumento nos rendimentos. Ações que contribuam à solução dos entraves levantados nesse estudo poderão ser oportunidades para o sucesso da cultura tanto para os municípios quanto para o Estado.

Termos para indexação: Fragaria x annanasa Duch.; produção comercial; rendimentos; agricultura familiar; potencialidade.

\section{Diagnosis of strawberry production in Santa Catarina in $\mathbf{2 0 1 5}$}

\begin{abstract}
This study aimed to identify and quantify the cultivated area, number of families involved in the production and the quantity of strawberries produced in the state of Santa Catarina during 2015. The work included the survey and data collected in field, through the use of questionnaires which were answered by Epagri's extension officers. The six Mesoregions (IBGE) had strawberry plantation for commercial production and for their own consumption. All together, 725 families were involved in the commercial strawberry production. Approximately 9918 tons of strawberries were produced in 225,3 ha. The crop has great potential for the high yields found as a result of the responses obtained in the questionnaire, with an estimated average of 35,6 to $38,6 \mathrm{t} \mathrm{ha-1}$ (IC=95\%).The results obtained in 2015 were contrasted with data from the 2016-2017 harvest in some regions of the state, which show a decrease in the area (ha) of strawberry cultivation, but an increase in yields. In addition, more studies in this field could contribute to understand better how to enhance the strawberry production.
\end{abstract}

Index terms: Fragaria $\mathrm{x}$ annanasa Duch; commercial production; crop yield; family farming, potential.

\section{Introdução}

Das pequenas frutas, entre as quais se encontram morango, framboesa, mirtilo, groselha e outras berries, o morango (Fragaria $\mathrm{x}$ annanasa Duch.) é a mais representativa, com $67 \%$ da produção mundial (FAOSTAT, 2020). Além de se destacar por seu aroma, sabor e valor nutricional (BADJAKOV et al., 2014), o morango desperta a atenção dos produtores e do mercado consumidor em escala mundial (HUMMER \& HANCOCK, 2009), com tendência crescente de cultivo e produção. A cultura do morangueiro se sobressai por ser um cultivo microclimático (NERI et al., 2012), acessível aos pequenos produtores, carac- terizado pela grande exigência em mão de obra, baixos custos de implantação e manejo, gerando bom retorno econômico a curto prazo (RONQUE, 1998; MADAIL et al., 2007; BIASIO et al., 2015; SAMTANI et al., 2019).

No Brasil, a cultura do morangueiro tem se concentrado em regiões serranas típicas de clima temperado e próximas a grandes centros metropolitanos por questões de logística e comercialização (ALMEIDA et al., 2009). A Região Sul do Brasil tem o consumo per capita mais alto em relação a outras regiões, sendo o estado de Santa Catarina o quinto maior consumidor nacional com 0,221 $\mathrm{kg}$ ano $^{-1}$ (IBGE, 2010).

O município de Rancho Queimado, pertencente à Mesorregião da Grande Florianópolis, é considerado como Capital Catarinense do Morango pela Lei Estadual № 11.954/2001, consolidada pela Lei $N^{\circ} 16.722 / 2015$ (BRASIL, 2015); outros municípios destacados pela produção no Estado são Urupema, São Joaquim, Urubici, Bom Jardim da Serra, Bom Retiro, Capão Alto, Campo Belo do Sul e Lages da Mesorregião Serrana, cujo período de colheita permite obter melhores preços em épocas com escassa oferta do produto (FAGHERAZZI, 2013; FAGHERAZZI et al., 2014).

Por ser um cultivo tipicamente de exploração familiar, dados confiáveis sobre a cultura tornam-se de difícil obtenção. Assim, objetivou-se com este

Recebido em 27/11/2019. Aceito para publicação em 30/6/2020.

${ }^{1}$ Esta pesquisa é parte da dissertação de mestrado da primeira Autora

${ }^{2}$ Engenheira-agrônoma, M.Sc., UFSC/Centro de Ciências Agrárias, Rod. Admar Gonzaga, 1346, Itacorubi, Florianópolis, SC, 88034-000, fone: (48) 37215424, e-mail: anyela.rmolina@gmail.com.

${ }^{3}$ Engenheira-agrônoma, Dra., Epagri/Centro de Informações de Recursos Ambientais e de Hidrometeorologia de Santa Catarina (CIRAM), Rod. Admar Gonzaga, 1387, Florianópolis/SC, 88134901, fone: (48) 36655134, e-mail: cristina@epagri.sc.gov.br, wilianricce@epagri.sc.gov.br.

${ }^{4}$ Engenheiro-agrônomo, Dr., UFSC/Centro de Ciências Agrárias, E-mail: aparecido.silva@ufsc.br. 
trabalho identificar e quantificar a área cultivada, a quantidade produzida e o número de famílias envolvidas na produção comercial de morangos no ano de 2015 no estado de Santa Catarina.

\section{Material e métodos}

Foi realizado um levantamento de informações a campo sobre as regiões de cultivo de morango no estado de Santa Catarina durante o ano de 2015. $O$ instrumento de coleta dos dados foi um questionário estruturado utilizandose o aplicativo conhecido como Formulários Google (GOOGLE, 2016). O formulário foi enviado on-line aos extensionistas da Epagri de cada um dos 295 municípios do Estado, sendo aplicado um questionário por município, respondido pelo extensionista com as informações correspondentes ao município em questão. Também foi incluído um espaço para que os extensionistas respondentes pudessem registrar informações que julgassem ser importantes além daquelas solicitadas no questionário.

O questionário foi composto por perguntas abertas e fechadas, abrangendo temas como: presença de cultivo, época de início da cultura no município, número de produtores/famílias dedicadas à produção de morangueiro, área com produção de morango, rendimentos na área, entre outros. Após coletadas, as informações foram tabuladas e sistematizadas em planilha eletrônica para apresentação em gráficos e tabelas. Além disso, foram utilizadas estatísticas descritivas para sumarização das informações no programa Excel ${ }^{\circledR}$. Os dados apresentados nesse artigo fazem referência à parte das informações levantadas no questionário original. Para a estimativa da média de rendimento de cultivos comerciais foi calculado o intervalo de confiança com 95\% de confiabilidade.

\section{Resultados e discussão}

Dos 295 questionários esperados para o estado de Santa Catarina, foram respondidos 172 , dos quais 85 responderam ter produção comercial de morangueiro no ano de 2015 . Todavia, no início do questionário, para aqueles que não tinham produção, havia uma pergunta a qual tratava sobre a possibilidade de ter ocorrido cultivo no passado e os motivos do encerramento da atividade. No entanto, ressalta-se que alguns municípios não responderam ao questionário, pelo que foi realizada ligação telefônica, e os técnicos responderam que, devido à produção do município ser de pouca expressão, ou por não terem conhecimento de produção de morango nos municípios, seria desnecessário responder o questionário.

\section{Estimativa da produção de morango no Estado de Santa Catarina em 2015}

A proporção de respondentes para aqueles que cultivam morangueiro foi de 71,4\%, ou seja, dos 119 municípios que plantam em Santa Catarina, 85 responderam ao questionário. Dos municípios que responderam não ter produção comercial, 24 tiveram produção comercial em anos anteriores e dentro da classe "sem produção comercial", independente das subclasses "já teve" ou "nunca teve", 20 mencionaram produção para autoconsumo, incipiente ou ocasional em 2015 (Tabela 1).

A produção para autoconsumo abrangeu hortas caseiras e em alguns municípios o excedente é vendido na cidade. Esse tipo de produção apresenta grande relevância na agricultura familiar, sendo uma forma de economizar recursos financieiros e que tem grande importância para a segurança alimentar (GRISA \& SCHNEIDER, 2008).

Com base no questionário aplicado nesse trabalho, a produção comercial de morango no estado de Santa Catarina teve o início no Sul Catarinense, no ano de 1982 em São João do Sul. Na Mesorregião Serrana, em 1986, no município de Bom Retiro. Nas outras quatro mesorregiões produtoras, o cultivo foi iniciado na década de 90. Durante os anos de 1990 a 2000, 25 municípios começaram a cultivar morangos, e entre os anos de 2001 até 2010, ocorreu o envolvimento de mais 34 municípios. No período compreendido entre 2011 até

Tabela 1. Total de municípios respondentes com e sem produção de morango no Estado de Santa Catarina no ano de 2015 distribuído por Mesorregiões (IBGE). Epagri, Florianópolis

Table 1. Total of municipalities distributed by Mesoregions with and without strawberry production in the Santa Catarina state - 2015. Epagri, Florianópolis

\begin{tabular}{|c|c|c|c|c|c|}
\hline Mesorregião & $\begin{array}{c}\text { Com } \\
\text { produção } \\
\text { comercial de } \\
\text { morango }\end{array}$ & $\begin{array}{c}\text { Sem } \\
\text { produção } \\
\text { comercial de } \\
\text { morango }\end{array}$ & & & $\begin{array}{l}\text { Produção para } \\
\text { autoconsumo, }\end{array}$ \\
\hline & Total & Já teve & $\begin{array}{c}\text { Nunca } \\
\text { teve }\end{array}$ & Total & $\begin{array}{c}\text { incipiente ou } \\
\text { ocasional* }\end{array}$ \\
\hline Grande Florianópolis & 4 & 1 & 1 & 2 & 1 \\
\hline Norte Catarinense & 11 & 1 & 1 & 2 & -- \\
\hline Oeste Catarinense & 30 & 7 & 30 & 37 & 10 \\
\hline Serrana & 17 & 1 & 5 & 6 & -- \\
\hline Sul Catarinense & 13 & 6 & 17 & 23 & 3 \\
\hline Vale do Itajaí & 10 & 8 & 9 & 17 & 6 \\
\hline Total & 85 & 24 & 63 & 87 & 20 \\
\hline Total (\%) & 49,4 & 14,0 & 36,6 & 50,6 & 11,6 \\
\hline
\end{tabular}

* Valor incluso na classe "sem produção comercial", independente da sub-classe "já teve" ou "nunca teve". 


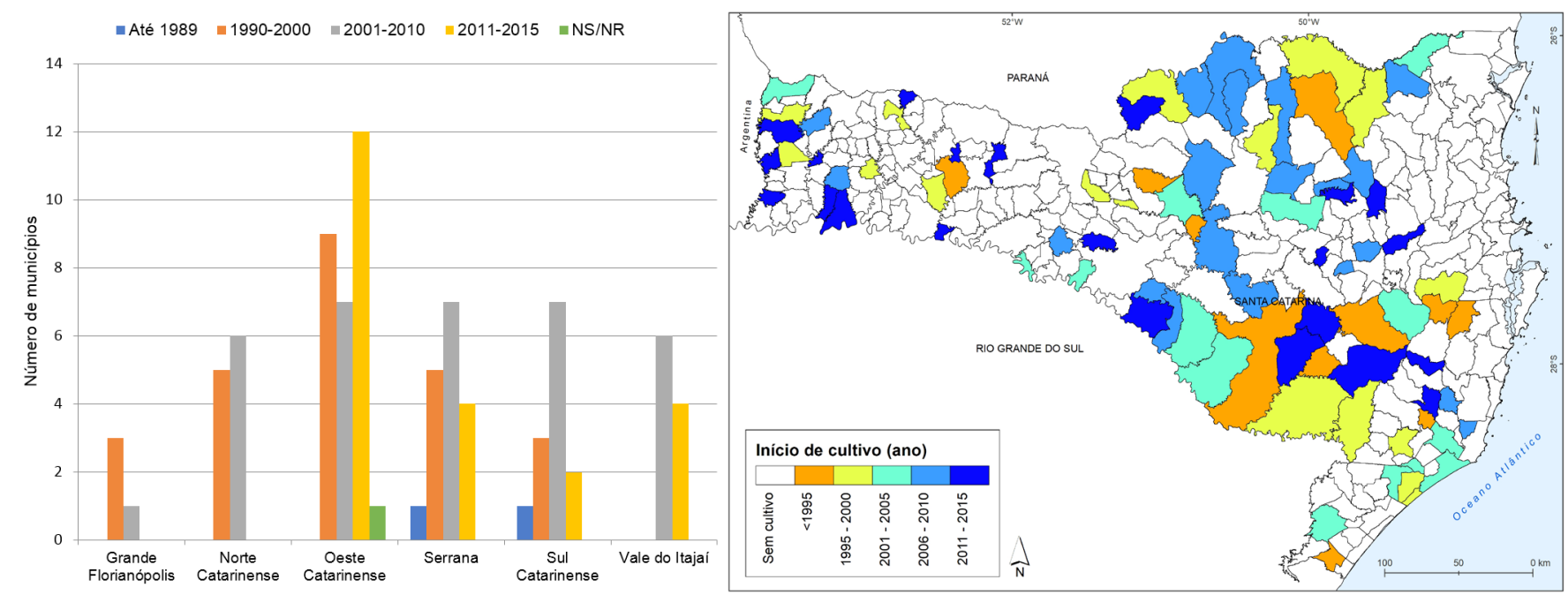

Figura 1. Época de início do cultivo comercial de morango no estado de Santa Catarina por mesorregiões: A. Número de municípios com produção comercial de morango - B. Ano de início de cultivo por município. Epagri, Florianópolis

Figure 1. Time of beginning of commercial strawberry production in the state of Santa Catarina by mesoregions: A. Number of municipalities with commercial strawberry production - B. Year of beginning of cultivation by municipality. Epagri, Florianopolis

2015, outros 22 municípios iniciaram produção comercial (Figura 1).

\section{Municípios com produção}

Em 2015, a cultura do morango ocupou área em torno de 225,9ha, com produção de 9.918t (Tabela 2). A área com produção de morango é menor quando comparada com os outros esta- dos da Região Sul, como o Rio Grande do Sul cuja área é de 600 ha (FAGHERAZZI et al., 2014). A produção em SC relatada pelos extensionistas em 2015 foi maior à reportada no Censo Agropecuário de 2017, sendo estimada em 5.481t (BGE, 2019), mas observa-se que, quando comparados aos dados relatados nos demais estados do Sul do Brasil, os valores foram também meno-
Tabela 2. Área, produção total e número de famílias relatados nas regiões produtoras de morango do estado de Santa Catarina, agrupados por Mesorregiões, segundo as respostas dos questionários aplicados no estado - Ano 2015. Epagri, Florianópolis

Table 2. Area, total production and number of families reported in the strawberry producing regions of Santa Catarina State, grouped by Mesoregions according to the answers to the questionnaires applied in the state - 2015. Epagri, Florianópolis

\begin{tabular}{lccc}
\hline Mesorregião & $\begin{array}{c}\text { Estimativa de } \\
\text { área plantada } \\
\text { (ha) }\end{array}$ & $\begin{array}{c}\text { Estimativa de } \\
\text { Produção (t) }\end{array}$ & $\begin{array}{c}\text { Número de produtores } \\
\text { ou fálias envolvidas na } \\
\text { produção comercial do } \\
\text { morango }\end{array}$ \\
\hline Grande Florianópolis & 72,3 & 4270,0 & 251 \\
Norte Catarinense & 17,8 & 782,0 & 178 \\
Oeste Catarinense & 47,7 & 2021,7 & 102 \\
Serrana & 50,7 & 1778,4 & 40 \\
Sul Catarinense & 34,3 & 1012,8 & 18 \\
Vale do Itajaí & 2,6 & 53,1 & 725 \\
\hline Total & 225,3 & 9918,0 & \\
\hline
\end{tabular}

res aos reportados por outros autores. Por exemplo, Paraná e o Rio Grande do Sul apresentaram produções de $7.989 t$ e 13.256t respectivamente (IBGE, 2017), embora estes dados contrastem quando comparados com outras fontes: a produção do Paraná registrada em 2017 foi de 26.120t (PARANÁ, 2017). Na Tabela 2 podem ser observadas as produções comerciais de morango em cada uma das mesorregiões do IBGE. O valor médio estimado para o rendimento do morango dos cultivos comerciais em 2015, com base nas informações recebidas nos questionários, foi de 35,6 a $38,6 \mathrm{t} \mathrm{ha}^{-1}$ (IC=95\%).

A produção comercial de morango encontra-se distribuída em todo o Estado, sendo maior na Grande Florianópolis, responsável por $43 \%$ da produção estadual com 72,3ha dedicados à cultura do morangueiro no ano de 2015 (Tabela 2). Em outros estados produtores, como Minas Gerais, a microrregião de Pouso Alegre é responsável por $90 \%$ da produção da fruta, aumentando a área plantada de 172,5 a $1.325 \mathrm{ha}$, entre 1990 e 2004, respectivamente (ANDRADE \& BRANDÃO, 2013).

Dos municípios produtores que responderam ao questionário, os de maior área cultivada foram: Rancho Queimado $(50,0$ ha), São João do Sul $(20,0$ ha), Águas Mornas (16,3ha), Lages $(15,0 \mathrm{ha})$ e Pinheiro Preto (13,0ha), e os de maior produção total são Rancho Queimado (3000t), Águas Mornas (1.000t), Frai-॰ 

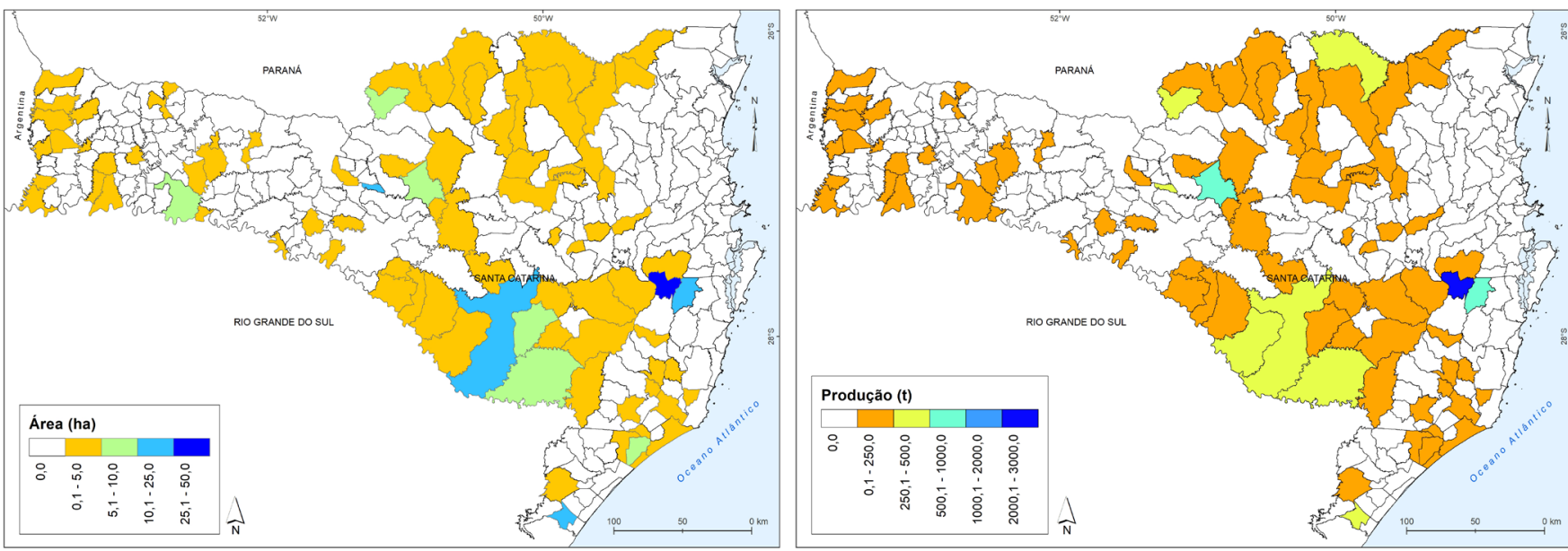

Figura 2. Área (ha) (A) e Produção (t) (B) de morango por município no estado de Santa Catarina - Ano 2015. Epagri, Florianópolis Figure 2. Area $(A)$ and production $(B)$ of strawberry ( $t$ ) by municipality in the state of Santa Catarina - Year 2015. Epagri, Florianópolis

burgo (600t), Lages (450 t) e São João do Sul (360t) (Figura 2).

$O$ rendimento estimado do morango no Estado obtido em 2015 (36,7 \pm 1,05 t ha ${ }^{-1}$; IC $=95 \%$ ) é um valor considerado alto e acima da média nacional de 30,0t ha $^{-1}$ (FAGHERAZZI et al., 2014). Pode-se observar que o rendimento médio está aquém de outros países, como Estados Unidos $\left(65,1 \mathrm{t} \mathrm{ha}^{-1}\right)$, Espanha $\left(49,0 \mathrm{t} \mathrm{ha}^{-1}\right)$ e México $\left(47,9 \mathrm{t} \mathrm{ha}^{-1}\right)$, países com maior produção mundial (FAOSTAT, 2020). Em relação aos países vizinhos da América do Sul, as médias são similares às observadas no Uruguai $\left(35,0\right.$ a $\left.45,0 \mathrm{t} \mathrm{ha}^{-1}\right)$ (GIMENEZ et al., 2012) e no Chile (média nacional 32,0t ha-1) (RETAMALES \& REYES, 2012). No Oeste Catarinense, utilizando produção orgânica, foram obtidos rendimentos médios de $39,5 \mathrm{t} \mathrm{ha}^{-1}$ de frutas comerciais (BRUGNARA et al., 2011); trabalhos no Rio Grande do Sul em transição ecológica obtiveram 34,4 e 38,9t ha ${ }^{-1}$ (MARTINS et al., 2011) e em produção convencional entre 30,0 e 44,0t ha-1 (e 44,0t ha-1 (ANTUNES et al., 2010).

Foram relatados pelos municípios alguns fatores devido aos quais não havia produção comercial de morango no ano de 2015 (Tabela 3). Do total dos questionários respondidos, 63 municípios nunca tiveram produção comercial de

Tabela 3. Fatores que inibem a produção de morango nos municipios pertences às Mesorregiões (IBGE) do Estado de Santa Catarina - Ano 2015 Epagri, Florianópolis

Table 3. Factors that inhibit strawberry production in the municipalities within the Mesoregions of the state of Santa Catarina - 2015, Epagri, Florianópolis

\begin{tabular}{|c|c|c|c|c|c|c|}
\hline Mão de obra & & & $x$ & & $x$ & $x$ \\
\hline Comercialização & & & $x$ & $x$ & $x$ & $x$ \\
\hline Demanda atendida por outros municípios & & & $x$ & & & \\
\hline Falta de conhecimento técnico & & & $x$ & & $x$ & $x$ \\
\hline Pragas e doenças & & & & & $x$ & $x$ \\
\hline Produção comercial eventual & & & $x$ & & & \\
\hline $\begin{array}{l}\text { Planeja futuramente iniciar cultivo } \\
\text { comercial }\end{array}$ & & & $\mathrm{x}$ & & & \\
\hline
\end{tabular}


morango (Tabela 1). Observa-se que nos municípios onde o morango não é cultivado que isso acontece por questões tradicionais. São regiões onde há produção de gado, fumo, arroz, milho e outras hortaliças. Foi relatado pelos extensionistas que a produção de morango não se encaixa com o perfil dos agricultores e não atrai tanto interesse. A segunda causa mais comum relatada nos municípios não produtores de morango está ligada à comercialização, como a alta perecibilidade dos morangos, somada à necessidade de capacitação e estruturas para a colheita e a pós-colheita. A falta de mão de obra é outro fator que dificulta a produção, podendo tornar a produção comercial inviável, sendo esta a resposta mais comum no Oeste Catarinense.

Outro entrave relatado pelos extensionistas para o sucesso da cultura em alguns municípios é a incidência de pragas e doenças, pois as condições climáticas favoráveis ao seu desenvolvimento e a maior necessidade da aplicação de agrotóxicos para o controle fitossanitário fazem com que a cultura seja de pouco interesse para os produtores de alguns municípios. Foi relatado pelos extensionistas que a incidência de fun- gos e ácaros são as principais razões pela desistência por parte dos produtores, dificultando a produção de morangueiro de forma comercial. Os extensionistas dos municípios do Oeste Catarinense relataram que alguns produtores futuramente deverão iniciar ou retornarão à cultura do morangueiro. Várias das respostas ressaltam a importância da assistência técnica como instrumento para resolver os gargalos específicos de cada local para a produção de morango. Henz (2010) ressalta o sucesso que teve a cultura do morangueiro no Espírito Santo devido às ações da Secretaria de Agricultura e do Instituto Capixaba de Pesquisa, Assistência Técnica e Extensão Rural (Incaper) em relação ao aprimoramento da assistência técnica, a disponibilização de mudas, cultivares, cadastramento de produtores e marcas para caracterizar a produção de morango e defini-lo como um produto diferenciado.

\section{Produtores e famílias envolvidas}

O total de famílias e/ou produtores envolvidos na produção comercial de morangos foi de 725 famílias, sendo

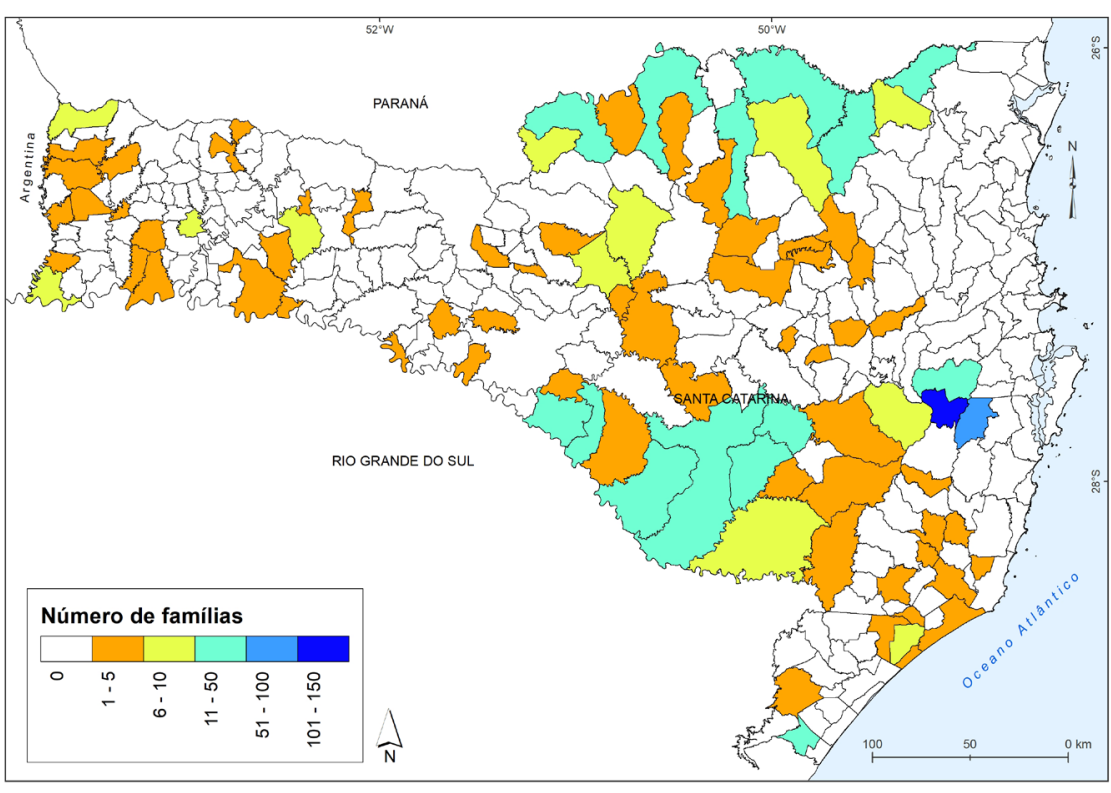

Figura 3. Número de famílias envolvidas por cidade com a produção comercial de morango no estado de Santa Catarina - Ano 2015. Epagri, Florianópolis

Figure 3. Number of families involved with commercial strawberry production by municipality in the state of Santa Catarina - Year 2015. Epagri, Florianópolis equivalente a 3,2 famílias por hectare (Figura 3). O Censo Agropecuário de 2017 relata que, em Santa Catarina, $50,68 \%$ da produção estadual é proveniente da agricultura familiar (IBGE, 2019). Na cultura do morangueiro é característico o uso intensivo de mão de obra para as atividades próprias da atividade (MADAlL et al., 2007) e agricultores familiares produzem mais de $90 \%$ da produção de morango no Brasil (HENZ, 2010). Todavia, no espaço reservado para os comentários dos extensionistas, foi relatado que há mais famílias interessadas em iniciar a produção de morango, o que permite observar o interesse crescente pela cultura em Santa Catarina.

\section{Conclusões}

Para o ano de 2015, 9.918 toneladas de morangos foram produzidas em 225,9 hectares, o que representa rendimento médio comercial estimado variando entre 35,6 a $38,6 t$ ha $^{-1}$ (IC=95\%).

As seis mesorregiões apresentaram produção comercial de morangueiro, destacando-se a produção da Grande Florianópolis, do Oeste Catarinense, da Serrana e do Sul Catarinense, com participação na produção estadual de $43,1 \%$, $20,4 \%, 17,9 \%$ e $10,2 \%$ respectivamente.

A agricultura familiar apresenta grande relevância na produção comercial do morango, envolvendo 725 famílias na produção comercial do Estado.

\section{Agradecimentos}

Agradecemos à Capes pela concessão da Bolsa de pesquisa da primeira autora, e ao Departamento Estadual de Extensão Rural e Pesqueira - DERP, pelo apoio recebido na época de envio dos questionários aos extensionistas e pelo apoio na motivação para participação nessa pesquisa.

\section{Referências}

ALMEIDA, I. R. de; STEINMETZ, S.; ANTUNES, L. E. C.; FILIPPINI ALBA, J. M.; MATZENAUER, R.; RADIN, B. Zoneamento agroclimático para produção de morango no Rio Grande do Sul. Embrapa Clima Temperado. Documentos, v. 283, p. 28, 2009. 
ANDRADE, A.C.D.; BRANDÃO, A.T.J. Novas Dinâmicas Econômicas Nos Espaços Rurais Da Microrregião De Pouso Alegre (MG): A Produção de Morango no Município de Bom Repouso. Revista de Geografia, v. 3, n. 1, p. 1-7. 2013.

ANTUNES, L. E. C. RISTOW, N.C.; KROLOW, A.C.R.; CARPENEDO, S.; REISSER JÚNIOR, $C$. Yield and quality of strawberry cultivars. Horticultura Brasileira, v. 28, p. 222-226, 2010. Disponível em: https://www.scielo.br/ pdf/hb/v28n2/a15v28n2.pdf . Acesso em: 10 jun 2020. DOI: https://doi.org/10.1590/ s0102-05362010000200015.

BADJAKOV, I. NIKOLOVA, M. GEVRENOVA, R.; KONDAKOVA, V.; TODOROVSKA, E.; ATANASSOV, A. Bioactive Compounds in small Fruits and their Influence on Human Health. Biotechnology \& Biotechnological Equipment, v. 22 , n. 1, p. 581-587, 2014. DOI: https:// doi.org/10.1080/13102818.2008.10817517

BIASIO, R.; DANI, D.; ECKERT, A.; MECCA, M.S. Determinação do custo e da rentabilidade na cultura do morango em uma pequena propriedade agrícola situada em Flores da Cunha/RS. Custos e @gronegócio on line. v. 11, n. 1, Jan/Mar. 2015.

BRASIL. Lei $\mathrm{n}^{\circ} \mathbf{1 6 . 7 2 2}$, de 8 de Outubro de 2015. Disponível em: http://leis.alesc.sc.gov. br/html/2015/16722_2015_Lei_promulgada.html . Acesso em: 31 mar 2020.

BRUGNARA, E. C. NESI, C.N.; HAVEROTH, C. SCHWENGBER, J. E.; VERONA, L. A. F. Produção Orgânica de Diferentes Cultivares de Morangueiro Cultivados em Solo Coberto com Acículas de Pínus e Plástico Preto na Região de Chapecó, SC. Embrapa Clima Temperado. Boletim de pesquisa e desenvolvimento, v. 133, p. 20 p., 2011. Disponível em: http://www.infoteca.cnptia.embrapa. br/infoteca/handle/doc/921037. Acesso em: 10 jun 2020.

ESTADO DO PARANÁ. Valor Bruto da Produção Rural Paranaense 2017. 36p., 2017. Disponível em: http://www.agricultura.pr.gov.br/sites/default/arquivos_restritos/files/documento/2019-09/vbp2017analisecompletavd.pdf. Acesso em: 2 abril 2020.

FAGHERAZZI, A. F. Avaliação de cultivares de morangueiro no Planalto Sul Catarinense. [s.l.] Universidade do Estado de Santa Catarina, 2013.
FAGHERAZZI, A. F. COCCO, Ca.; ANTUNES, L.E.C.; SOUZA, J.A.; RUFATO, L. La fragolicoltura brasiliana guarda avanti. Frutticoltura, v.6, p.20-25, 2014.

FAOSTAT. Crop statistics. Strawberries, Raspberries, Cranberries, Blueberries, Currants, Gooseberries, Berries nes. Disponível em: http://www.fao.org/faostat/en/\#data . Acesso em: 31 mar 2020.

Formulários da Google. Disponível em: (https://www.google.com/intx/pt-BR/work/ apps/business/products/forms/). Acesso em: 15 mar 2015.

GIMENEZ, G.; VICENTE, E.; MANZZIONI, A.; et al. Mejoramiento y Desarrollo de cultivares de frutilla en Uruguay. In: SIMPOSIO NACIONAL DO MORANGO- ENCONTRO SOBRE PEQUENAS FRUTAS E FRUTAS NATIVAS DO MERCOSUL, 6‥5‥, Pelotas. Anais[...] Palestra. Pelotas, Embrapa Clima Temperado. 2012. p. 219-222.

GRISA, C.; SCHNEIDER, S. "Plantar pro gasto": a importância do autoconsumo entre famílias de agricultores do Rio Grande do Sul. Rev. Econ. Sociol. Rural [online]. 2008, vol.46, n.2, pp.481-515. ISSN 18069479. DOI: https://doi.org/10.1590/S010320032008000200008.

HENZ, G.P. Desafios enfrentados por agricultores familiares na produção de morango no Distrito Federal. Horticultura Brasileira, v. 28, n. 3, p. 260-265, 2010.

HUMMER, K.E.; HANCOCK, J. Strawberry Genomics: Botanical History, Cultivation, Traditional Breeding, and New Technologies. In: FOLTA, K. M.; GARDINER, S. E. (Eds.). Genetics and Genomics of Rosaceae. p. 413-435. 2009.

IBGE - INSTITUTO BRASILEIRO DE GEOGRAFIA E ESTATÍSTICA. . Censo Agropecuário 2017 Resultados Definitivos IBGE. 2019. Disponivel em: https://biblioteca.ibge.gov.br/ visualizacao/periodicos/3096/agro_2017_ resultados_definitivos.pdf. Acesso em: 31 mar 2020.

IBGE- INSTITUTO BRASILEIRO DE GEOGRAFIA E ESTATÍSTICA. Número de estabelecimentos agropecuários e quantidade produzida por produtos da horticultura - resultados preliminares 2017. Disponível em: https://sidra.ibge.gov.br/tabela/6619 . Acesso em: 31 mar 2020.
IBGE - INSTITUTO BRASILEIRO DE GEOGRAFIA E ESTATÍSTICA. Pesquisas de orçamentos familiares 2008-2009. v.1 2010. Disponível em: http://www.ibge.gov.br/home/ estatistica/populacao/condicaodevida/ pof/2008_2009/POFpublicacao.pdf. Acesso em : 20 nov 2015.

MADAIL, J.C.M.; ANTUNES, L.E.C.; BELARMINO, L.C.; et al. Avaliação Econômica dos Sistemas de Produção de Morango: Convencional, Integrado e Orgânico. Embrapa Clima Temperado. Comunicado tecnico 181. $4 p$. 2007.

MARTINS, D.D.S.; SCHWENGBER, J.E.; STRASSBURGER, A.S. O cultivo do morangueiro em sistema de transição ecológica : componentes do rendimento e incidência de doenças. Revista Brasileira de Agroecologia, v. 6, n. 1, 2011. Disponível em: http://revistas.abaagroecologia.org.br/index.php/rbagroecologia/article/view/9960. Acesso em: 10 jun 2020.

NERI, D. BARUZZI, G.; MASSETANI, F.; FAEDI, W. Strawberry production in forced and protected culture in Europe as a response to climate change. Canadian Journal of Plant Science, v. 92, n. 6, p. 1021-1036, 2012. Disponível em: https://www.nrcresearchpress. com/doi/pdfplus/10.4141/cjps2011-276 Acesso em: 10 jun 2020. DOI: https://doi. org/10.4141/cjps2011-276.

RETAMALES, J.B.; REYES, M. Berry industry in Chile: Past, Present and Future. In: VI SIMPOSIO NACIONAL DO MORANGO E $\checkmark$ ENCONTRO SOBRE PEQUENAS FRUTAS E FRUTAS NATIVAS DO MERCOSUL. Anais[...] Pelotas, 2012. p.198-203.

RONQUE, E.R.V. Cultura do morangueiro: revisão e prática. Curitiba: Emater, 1998. $206 p$.

SAMTANI, J.B.; ROM, C.R.; FRIEDRICH, H.; FENNIMORE, S.A.; FINN, C.E.; PETRAN, A.; WALLACE, R.W.; PRITTS, M.P.; FERNANDEZ, G.; CHASE, C.A. The Status and Future of the Strawberry Industry in the United States. Horttechnology, v. 29, n. 1, p.11-24, fev. 2019. DOI: http://dx.doi.org/10.21273/horttech04135-18. 